\title{
Genetic Basis of the Association of Sulphonamide Resistance with Methionine Auxotrophy in Neisseria gonorrhoeae
}

\author{
By B. WESLEY CATLIN† \\ Department of Microbiology, Medical College of Wisconsin, Milwaukee, WI 53226, USA
}

(Received 23 August 1988; revised 19 December 1988; accepted 13 January 1989)

\begin{abstract}
Selection by sulphonamides was investigated in Neisseria gonorrhoeae because a sulphonamideresistant $\left(\mathrm{Sul}^{\mathrm{r}}\right)$, methionine-requiring $\left(\mathrm{Met}^{-}\right)$phenotype that was common in the era of sulphonamide therapy became rare in the penicillin era. Cultures of wild-type $\left(\mathrm{Sul}^{\mathrm{s}} \mathrm{Met}^{+}\right)$ gonococci on a conventional medium containing sulphadiazine $\left(2-10 \mu \mathrm{g} \mathrm{ml}^{-1}\right)$ yielded numerous, nonidentical mutations of two met genes. The requirement of MetI $^{-}$mutants was satisfied only by methionine, whereas MetII $^{-}$mutants utilized either homocysteine or methionine. My theory that increased resistance to sulphonamides is a pleiotropic effect of methionine auxotrophy was confirmed by the return of sulphonamide susceptibility in all $\mathrm{Met}^{+}$ spontaneous mutants. Furthermore, the Sulr ${ }^{r} \mathrm{Met}^{-}$traits were introduced or eliminated together by DNA-mediated transformation. Sulphonamides are known to inhibit dihydropteroate synthase; consequently, they interrupt the entire sequence of reactions in the folate pathway including the methyl group transfer from $N^{5}$-methyltetrahydrofolate to homocysteine to form methionine. The increased sulphonamide resistance of these $\mathrm{Met}^{-}$mutants is discussed in terms of conservation of the pool of essential tetrahydrofolate derivatives. The ease with which spontaneous forward and reverse met mutations can be obtained is unique among gonococcal genes.
\end{abstract}

\section{INTRODUCTION}

The treatment of gonorrhoea with sulphanilamide commenced in 1937 (Dees \& Colston, 1937). Thereafter, sulphadiazine and other improved sulphonamides were introduced and widely employed, but their effectiveness was curtailed increasingly by the development of resistance (Catlin, 1976). The advent of penicillin treatment was followed by a reduction of sulphonamide-resistant (Sul ${ }^{r}$ ) Neisseria gonorrhoeae from a peak of $85 \%$ in $1949-1950$ to $5 \%$ of strains examined ten years later (Reyn, 1961). Recent tests of the nutritional requirements of gonococcal strains isolated over a period of 40 years revealed that methionine auxotrophy was very common in the sulphonamide era, but had largely disappeared by 1970 (Catlin \& Reyn, 1982; Knapp et al., 1985).

The antibacterial effect of sulphonamides is due to inhibition of dihydropteroate synthase by binding to this target enzyme in competition with $p$-aminobenzoate, as foreseen in 1940 by Woods (1962). Dihydropteroate synthase performs an essential role in the biosynthesis of folates by condensing $p$-aminobenzoate with 2-amino-4-hydroxy-6-hydroxymethyl-7,8-dihydropteridine pyrophosphate to yield dihydropteroate (Gale et al., 1981) (Fig. 1). Furthermore, dihydropteroate synthase can accept sulphonamide as an alternative substrate to form a stable sulphonamide-containing dihydropteroate analogue (Brown, 1962). This product diffuses from Escherichia coli cells, thereby serving to deplete the pteridine pool (Roland et al., 1979). By reducing dihydropteroate availability, the sulphonamide affects the entire sequence of enzymecatalysed reactions in which the product of each reaction serves as the substrate for the next (Harvey, 1982). The final products of the folate pathway are essential for growth.

† Present address: 3550 Lebon Drive \#6420, San Diego, CA 92122-1058, USA. 


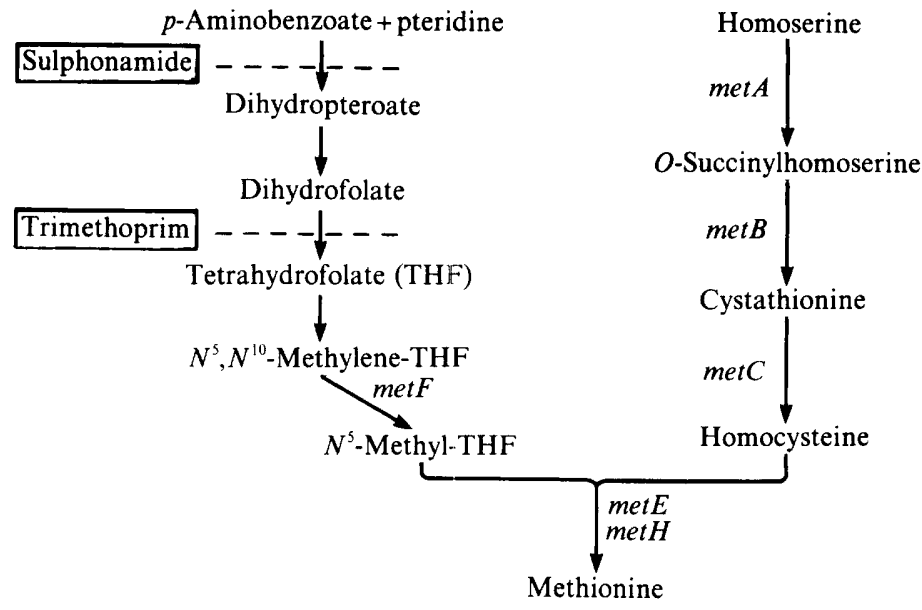

Fig. 1. Relation between the folate and methionine biosynthetic pathways in Escherichia coli. The solid arrows represent enzyme-catalysed reactions; broken lines indicate the sites of direct action of inhibitors.

Some mutations of $N$. gonorrhoeae (Ho et al., 1974), E. coli (Pato \& Brown, 1963) and Streptococcus pneumoniae (Lopez et al., 1987) result in structural alterations of dihydropteroate synthase. A reduction in the relative affinity of the $N$. gonorrhoeae dihydropteroate synthase for sulphonamide compared to $p$-aminobenzoate causes increased resistance. An additional mechanism of sulphonamide resistance in $E$. coli was postulated to involve methionine auxotrophy (Kohn \& Harris, 1942). Evidence for such a mechanism in Neisseria came from interspecific transformation experiments with DNAs from $\operatorname{Sul}^{r} N$. gonorrhoeae strains that had been isolated from patients in the 1940s (Catlin, 1967). N. meningitidis cells that were Suls and did not require methionine $\left(\mathrm{Met}^{+}\right)$were transformed to $\mathrm{Sul}^{\mathrm{r}} \mathrm{Met}^{-}$in a single step. This phenotype could be reversed to $\mathrm{Sul}^{\mathrm{s}} \mathrm{Met}^{+}$by parental DNA. Thus, the two traits were not separated by recombination. Confirmation that the Sulr DNA donor strains were $\mathrm{Met}^{-}$was obtained when a defined medium for growth of $N$. gonorrhoeae later became available (Catlin, 1973).

The relation between sulphonamide action and methionine biosynthesis is indicated in Fig. 1 and will be discussed hereafter. This communication examines the selection exerted by sulphonamides on $N$. gonorrhoeae. I describe the isolation and characteristics of certain met mutations, their profiles of recombination, and the return of susceptibility to sulphonamides that accompanies reversion to $\mathrm{Met}^{+}$.

\section{METHODS}

N. gonorrhoeae strains. Strain G10, isolated in 1937 from an eye-infection, is $\mathrm{Met}^{+} \mathrm{Arg}^{+} \mathrm{Pro}^{-}$(Catlin \& Reyn, 1982). Strain 89 was designated SS41835 when isolated in 1943 from a Danish patient; it is $\mathrm{Met}^{+} \mathrm{Arg}^{+} \mathrm{Pro}^{+}$and was used in genetic experiments by Koelbl \& Catlin (1986). Strains G10 and 89 are highly susceptible to sulphonamides (resistant to $0.5 \mu \mathrm{g}$ sulphadiazine $\mathrm{ml}^{-1}$ ) and are streptomycin-susceptible. Strain 251 was isolated in 1972 from a cervical specimen from a patient in Milwaukee, Wisconsin; it is $\mathrm{Met}^{+} \mathrm{ArgE}^{-} \mathrm{Pro}^{+} \mathrm{Sul}^{\text {s }}$ (resistant to $1.0 \mu \mathrm{g}$ sulphadiazine $\mathrm{ml}^{-1}$ ) and $\operatorname{Str}^{r}$ (resistant to streptomycin at a concentration $\geqslant 200 \mu \mathrm{g} \mathrm{ml}^{-1}$ ). Strain CDC, designated 78/002802 by the Centers for Disease Control, is $\mathrm{Met}^{+} \mathrm{Arg}^{+} \mathrm{Pro}^{-}$, resistant to $75 \mu \mathrm{g}$ sulphadiazine $\mathrm{ml}^{-1}$, and $\mathrm{Str}^{r}$. The identity of the bacteria as $N$. gonorrhoeae was confirmed by conventional methods (Catlin, 1978). Additional differences between strains 89 and 251 include the serological type of outer-membrane protein I (Catlin \& Shinners, 1985) and a five- to tenfold higher resistance of strain 251 than strain 89 to benzylpenicillin, oxacillin, erythromycin, tetracycline and chloramphenicol.

Media. GCMBS agar is GC medium base (Difco) with $1 \%(\mathrm{v} / \mathrm{v})$ White-Kellogg supplement added aseptically to the sterile molten medium (Catlin, 1978). GCMBS broth has the same composition as GCMBS agar, except for the omission of agar. 'Soft' agar is a mixture of equal volumes of GCMBS agar and GCMBS broth. NEDA (Neisseria 
defined agar) and the auxotyping media lacking various compounds possibly required for growth have been described (Catlin, 1973, 1978). NEDA-minus-Met is NEDA medium lacking added methionine. DEFT is a defined fluid for transformation that lacks methionine and various other compounds (Catlin, 1974; Koelbl \& Catlin, 1986).

Incubation and preservation of cultures. Inoculated media for genetic tests, auxotyping and other phenotype determinations were incubated at $36^{\circ} \mathrm{C}$ in an atmosphere of humidified air plus $8 \%(\mathrm{v} / \mathrm{v}) \mathrm{CO}_{2}$. The strains were preserved at $-60^{\circ} \mathrm{C}$ and revived, as described previously (Catlin, 1978).

Colony purification and multitip inoculation. The independent origin of mutants and transformants was assured by picking isolated colonies. Colonies were chosen that displayed the morphology indicative of piliation needed for competence in transformation (Catlin, 1974). Sul ${ }^{\mathrm{r}}$ gonococci were picked after incubation of sulphonamidecontaining agar for $1 \mathrm{~d}$ or $2 \mathrm{~d}$. They were transferred to a medium containing the sulphonamide at a concentration above that needed to inhibit the background parent cells, but below the concentration used for primary selection in order to avoid selecting second-step resistant mutants. Colonies from NEDA media were subcultured on the corresponding medium. GCMBS agar was used for a second subculture of isolated colonies from all media. In preparation for inoculating media with the Steers multitip replicating device (Catlin, 1978), growth from $16 \mathrm{~h}$ cultures was suspended homogeneously in DEFT to a density of $1-2 \times 10^{7}$ c.f.u. $\mathrm{ml}^{-1}$. A tenfold further dilution was made before filling the seed plate cups.

Sulphonamide resistance. The test compounds were sodium sulphadiazine (a gift from Lederle Laboratories, Pearl River, NY, USA, and also purchased from Sigma); sulphamethoxazole (a gift from Hoffmann-La Roche, Nutley, NJ, USA); and sodium sulphathiazole (from Sigma). Spontaneous mutation to resistance was determined quantitatively by inoculating a suspension of gonococci into liquefied soft agar containing the sulphonamide and immediately pipetting $4.0 \mathrm{ml}$ volumes on top of solidified GCMBS medium containing the corresponding sulphonamide concentration. The suspension was assayed for total c.f.u.. $\mathrm{ml}^{-1}$ in drug-free soft agar overlays. The apparent frequency of mutation was expressed as the ratio [no. of Sul colonies (after incubation for $3 \mathrm{~d})] /\left[10^{-6} \times\right.$ no. of Suls ${ }^{\mathrm{s}}$ c.f.u. inoculated]. It should be noted that the cellular divisions that occur before sulphonamide exerts its antibacterial action affect both the calculated mutation frequency and the assay of sulphonamide resistance.

To determine the level of gonococcal resistance, GCMBS agar containing a wide range of sulphonamide concentrations was inoculated with the aid of the multitip device. Each test site received 5-10 $10^{3} \mathrm{c}$.f.u. of the inoculum (prepared as described above). Resistance is given in terms of the highest concentration of the agent that permitted growth of part of the population (10 or more colonies) after incubation for $48 \mathrm{~h}$. A haze of growth at the inoculation site was disregarded.

Methionine pathway. L-Homoserine, $O$-succinyl-L-homoserine and L-cystathionine were used at final concentrations of $0.5 \mathrm{mM}$ and $0.05 \mathrm{mM}$. L-Homocysteine thiolactone hydrochloride was used at 0.8 or $0.5 \mathrm{mM}$. The final concentrations of crystalline vitamin B12 ranged between $0.01 \mathrm{~mm}$ and $0.00005 \mathrm{~mm}$. Solutions of these compounds were made up in sterile glass-distilled water on the day they were added to NEDA-minus-Met medium, which was freshly prepared. The complete NEDA medium contains $0.1 \mathrm{mM}$-L-methionine. $N$. gonorrhoeae has an absolute requirement for cysteine (Catlin, 1973) that is of interest since in E.colithe pathways for the biosynthesis of cysteine and $O$-succinylhomoserine converge in the formation of cystathionine (Smith, 1971). Multitip inoculation was used routinely, but all reported results were confirmed by streaking cellular suspensions on quadrants of methionine pathway media. Thus, the growth of isolated colonies could be inspected during incubation for $5 \mathrm{~d}$. The phenotypic designations $\mathrm{MetI}^{-}$and $\mathrm{MetII}^{-}$are given to the mutants pending characterization of the gene loci and their products. The test compounds were purchased from Calbiochem and Sigma.

Other traits. The phenotype of mutants was examined in order to assess the specificity of the forward and reverse met mutations. Auxotyping, which tests the capacity for growth on NEDA media lacking various compounds, has been described in detail (Catlin, 1978). Mutations of loci that lead to requirements for arginine $(\arg A, \arg E, \arg G)$, or uracil ( $\operatorname{pyr} B, \operatorname{pyr} E)$, or simultaneous requirements for arginine and uracil $(\operatorname{car} A, \operatorname{car} B)$ have been documented (Shinners \& Catlin, 1982). Other mutations in $N$. gonorrhoeae can impose requirements for hypoxanthine, proline, histidine, glutamine, lysine, threonine or thiamin pyrophosphate (Catlin, 1973, 1976; Catlin \& Reyn, 1982). In addition to tests for the biosynthetic functions encoded by these 14 genes, the responses to six antibacterial agents were examined routinely. These were gain (by strain 89 derivatives) or loss (by strain 251 derivatives) of resistance to streptomycin $\left(\geqslant 200 \mu \mathrm{g} \mathrm{ml}^{-1}\right)$; increased resistance to rifampin ( $\left.\geqslant 5 \mu \mathrm{g} \mathrm{ml}^{-1}\right)$, spectinomycin $\left(\geqslant 25 \mu \mathrm{g} \mathrm{ml}^{-1}\right)$ and nalidixic acid $\left(\geqslant 5 \mu \mathrm{g} \mathrm{ml}^{-1}\right)$; and loss of typical resistance to vancomycin $\left(3 \mu \mathrm{g} \mathrm{ml}^{-1}\right)$ and colistin $\left(5 \mu \mathrm{g} \mathrm{ml}^{-1}\right)$ (Koelbl \& Catlin, 1986).

Transformation. The methods for preparing DNA and performing transformation tests in DEFT fluid were as described by Koelbl \& Catlin (1986). Transformation results, such as those illustrated in Fig. 2, were obtained by use of a slightly modified semiquantitative plate method described earlier (Catlin, 1974). One or more sections of the inoculated NEDA-minus-Met medium were left without added DNA to detect the possible occurrence of 

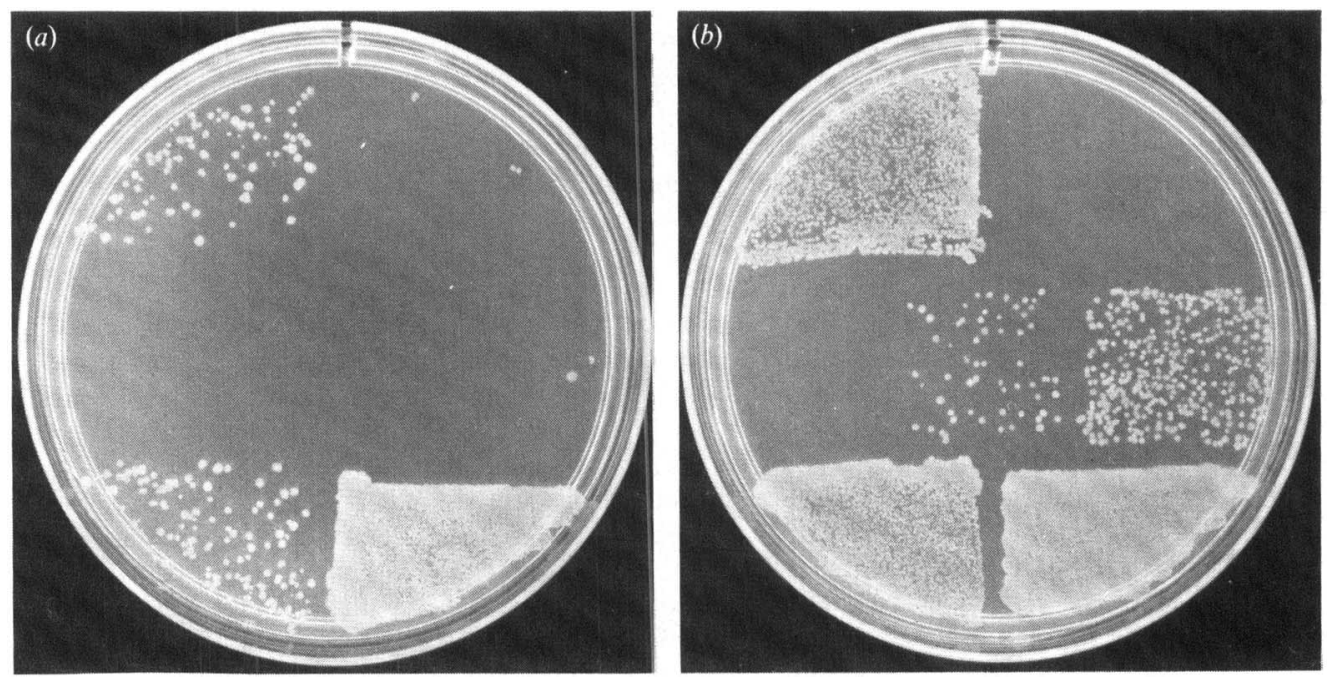

Fig. 2. $\mathrm{Met}^{+}$transformation obtained in crosses between MetI ${ }^{-}$mutants. All MetI ${ }^{-}$mutants were derived from $N$. gonorrhoeae strain 251, except 89-108, which was from strain 89 . An inoculum of $3.0 \times 10^{8}$ c.f.u. of mutant 2 (in $a$ ) or $1.5 \times 10^{8}$ c.f.u. of mutant 35 (in $b$ ) was uniformly spread to dryness on the surface of NEDA-minus-Met medium; solutions of donor DNA $(0.05 \mathrm{ml}$ containing 5 to $10 \mu \mathrm{g})$ were added and spread out. DNA donor strains for both $(a)$ and $(b)$ were: upper left, mutant 34 ; upper right, mutant 35 ; middle left, mutant 1 ; centre, mutant 2 ; middle right, mutant 56 ; lower left, mutant 89-108; lower right, $\mathrm{Met}^{+}$control DNA from parent strain 251.

$\mathrm{Met}^{+}$mutations. DNA from the $\mathrm{Met}^{+}$parent strain provided a positive control of recipient competence. Expression of the transformant phenotype occurs during the limited number of cellular divisions produced by Met ${ }^{-}$gonococci in the absence of methionine.

\section{RESULTS}

\section{Spontaneous mutations to sulphonamide resistance}

A limited number of bacterial divisions can occur in the presence of a concentration of sulphonamide that ultimately will be inhibitory (Gale et al., 1981; Roland et al., 1979; Woods, 1962). During this period of residual growth, which is due to the activities of preformed tetrahydrofolates, bacteria undergo mutations. The apparent frequency of mutation to increased resistance was determined for three $N$. gonorrhoeae strains (Table 1). Higher frequencies were found for strain 251 than for strains 89 or G10 on medium containing sulphadiazine at concentrations of 5 or $10 \mu \mathrm{g} \mathrm{ml}^{-1}$, in part because the slightly higher innate resistance of strain 251 permitted a longer period of residual growth. The mutation frequencies were inversely related to the concentration of sulphonamide.

Sul' mutants obtained in these tests were purified by repeated subculture of isolated colonies and examined for resistance and other characteristics. The levels of resistance differed for mutants selected on a given concentration of either sulphonamide. For example, resistance to sulphadiazine of strain 89 mutants ranged between $10 \mu \mathrm{g} \mathrm{ml}^{-1}$ (nine mutants) and $35 \mu \mathrm{g} \mathrm{ml}^{-1}$ (two mutants) for 31 colonies selected on $2 \mu \mathrm{g} \mathrm{ml}^{-1}$, and resistance to $35 \mu \mathrm{g} \mathrm{ml}^{-1}$ was found in 3 of 22 mutants and 6 of 42 mutants selected on 5 and $10 \mu \mathrm{g} \mathrm{ml}^{-1}$, respectively.

The large number of methionine-requiring mutants was the striking feature of these results (Table 1). Practically all of the strain $89 \mathrm{Sul}^{\mathrm{r}}$ mutants were $\mathrm{Met}^{-}$, as were large fractions of the strain 251 and G10 mutants. Methionine auxotrophs were also recovered in corresponding tests of two other Suls $N$. gonorrhoeae strains. In contrast, methionine auxotrophs were not found in exploratory tests of the well-known $N$. gonorrhoeae strain F62 inoculated on GCMBS medium 
Table 1. Apparent frequency of spontaneous mutation to sulphonamide resistance, and methionine requirement of mutants

$\begin{array}{clccc}\begin{array}{c}\text { Gonococcal } \\ \text { strain }\end{array} & \begin{array}{c}\text { Agent } \\ \left(\mu \mathrm{g} \mathrm{ml}^{-1}\right)\end{array} & \begin{array}{c}\text { Apparent } \\ \text { frequency }\end{array} & \begin{array}{c}\text { No. } \\ \text { examined }\end{array} & \begin{array}{c}\text { No. requiring } \\ \text { methioninef }\end{array} \\ & \text { SDZ, } 251 & \text { ND } & 38 & 17 \\ & \text { SDZ, } & 12 \cdot 23 & 42 & 8 \\ & \text { SDZ, 10 } & 1 \cdot 28 & 16 & 4 \\ & \text { SMX, 5 } & \text { ND } & 15 & 11 \\ & \text { SMX, 10 } & \text { ND } & 13 & 7 \\ 89 & \text { SMX, 20 } & 1 \cdot 21 & 5 & 5 \\ & \text { SDZ, 2 } & \text { ND } & 31 & 22 \\ & \text { SDZ, 5 } & 0 \cdot 69 & 22 & 42 \\ & \text { SDZ, 10 } & 0 \cdot 17 & 42 & 17 \\ \text { G10 } & \text { SMX, 2 } & 3.98 & 18 & 18 \\ & \text { SMX, 5 } & 1 \cdot 46 & 18 & 4\end{array}$

\footnotetext{
* Sulphadiazine (SDZ) or sulphamethoxazole (SMX) was incorporated at the indicated concentration in conventional GCMBS (bottom layer) agar and in molten GCMBS soft agar held at $46^{\circ} \mathrm{C}$; the latter was inoculated with the Suls ${ }^{\mathrm{s}} \mathrm{Met}^{+}$population and distributed in $4.0 \mathrm{ml}$ volumes on top of the solidified bottom layer in five or more Petri dishes.

$\dagger$ Apparent frequency expressed as the ratio [no. of Sul colonies (after incubation for $3 \mathrm{~d})]\left[\left[10^{-6} \times\right.\right.$ no. of Sul $^{\mathrm{s}}$ c.f.u. inoculated]. ND, Not determined.

$\ddagger$ Determined on NEDA-minus-Met medium inoculated with purified Sul mutants (described in Methods under Colony purification).
}

containing sulphadiazine at various concentrations. The $\mathrm{Met}^{-}$mutants, if any, presumably were not resistant to a concentration of sulphadiazine high enough to suppress multiplication of the parent strain, which is resistant to $50 \mu \mathrm{g} \mathrm{ml}^{-1}$.

\section{Characteristics of methionine auxotrophs}

A detailed study was made of $25 \mathrm{Met}^{-}$mutants found among the first $80 \mathrm{Sul}$ colonies picked from cultures of strain 251 after incubation for $1 \mathrm{~d}$ or $2 \mathrm{~d}$ on GCMBS medium containing sulphadiazine at 2 and $5 \mu \mathrm{g} \mathrm{m}^{-1}$ (Table 1). Increased resistance to sulphonamides and methionine auxotrophy were the only phenotypic traits that differentiated the mutants of strain 251 from the $\mathrm{Met}^{+} \mathrm{Arg}^{-} \mathrm{Str}^{\top}$ parent strain. Since these tests could detect possible mutations affecting 20 genes (cited in Methods), the results refuted the idea that sulphonamides were exerting a mutagenic action.

Nutritional requirements. Intermediate compounds in the classical methionine biosynthetic pathway (Fig. 1) were added separately to NEDA-minus-Met medium. Methionine was the sole utilizable compound for 11 of the strain 251 mutants and for mutant 89-108. These mutants, designated MetI-, are listed in Table 2. The other 14 mutants (Met $\mathrm{II}^{-}$) could use homocysteine for growth in place of methionine, but were unable to substitute vitamin B12, L-cystathionine, $O$-succinyl-L-homoserine or L-homoserine. $\mathrm{MetII}^{-}$mutants required homocysteine concentrations of 0.5 to $0.8 \mathrm{~mm}$ and incubation for up to $4 \mathrm{~d}$ for colonial diameters to equal the diameters of $2 \mathrm{~d}$ colonies on NEDA medium, which contains $0.1 \mathrm{~mm}$-methionine. Also, the growth of MetIImutants was slower than that of MetI- mutants on NEDA, and cellular lysis set in sooner.

Spontaneous reversion to met ${ }^{+}$. In the reversion tests, suspensions of $\mathrm{Met}^{-}$mutants containing $<4 \times 10^{8}$ c.f.u. were inoculated on numerous plates of NEDA-minus-Met medium to avoid overcrowding of the inoculum which could possibly inhibit colony-formation by revertants. All 14 metII mutations were subject to reversion. The apparent frequencies ranged between $0.08 \times 10^{-8}$ and $4.32 \times 10^{-8}$ for $12 \mathrm{MetII}^{-}$mutants (Table 2). Mutants 22 and 31 displayed very 
Table 2. Spontaneous reversion to $\mathrm{Met}^{+}$by $\mathrm{N}$. gonorrhoeae $\mathrm{MetI}^{-}$and $\mathrm{MetII}^{-}$mutants

NEDA-minus-Met medium in multiple Petri dishes was inoculated by spreading the surface uniformly with $0.1 \mathrm{ml}$ of each $\mathrm{Met}^{-}$cellular suspension made up in DEFT fluid; cultures were incubated at $36^{\circ} \mathrm{C}$ for $3 \mathrm{~d}$ in air plus $8 \% \mathrm{CO}_{2}$. All mutants were derived from strain 251 , except $89-108$, which was from strain 89 .

\begin{tabular}{|c|c|c|c|c|c|c|c|}
\hline $\begin{array}{c}\text { MetI- }^{-} \\
\text {mutant } \\
\text { designated : }\end{array}$ & $\begin{array}{c}10^{-8} \times \text { No. of } \\
\text { Met }^{-} \text {c.f.u. } \\
(A)\end{array}$ & $\begin{array}{l}\text { No. of } \mathrm{Met}^{+} \\
\text {revertants } \\
(B)\end{array}$ & $\begin{array}{c}\text { Ratio } \\
(B) /(A)\end{array}$ & $\begin{array}{c}\text { MetII- } \\
\text { mutant } \\
\text { designated: }\end{array}$ & $\begin{array}{c}10^{-8} \times \text { No. of } \\
\mathrm{Met}^{-} \text {c.f.u. } \\
(A)\end{array}$ & $\begin{array}{l}\text { No. of } \mathrm{Met}^{+} \\
\text {revertants } \\
\text { (B) }\end{array}$ & $\begin{array}{l}\text { Ratio } \\
(B) /(A)\end{array}$ \\
\hline $89-108$ & $11 \cdot 0$ & 2 & 0.18 & 3 & $8 \cdot 2$ & 4 & 0.49 \\
\hline 33 & $10 \cdot 3$ & 184 & 17.86 & 4 & $1 \cdot 2$ & 2 & 1.67 \\
\hline 34 & 3.8 & 12 & $3 \cdot 16$ & 5 & 4.9 & 2 & 0.41 \\
\hline 35 & 11.0 & 49 & $4 \cdot 45$ & 6 & $12 \cdot 5$ & 1 & 0.08 \\
\hline \multirow[t]{2}{*}{79} & $13 \cdot 1$ & 82 & $6 \cdot 26$ & 8 & 4.8 & 1 & 0.21 \\
\hline & & & & 21 & $20 \cdot 4$ & 2 & $0 \cdot 10$ \\
\hline 1 & $11 \cdot 5$ & 0 & 0 & 22 & 1.0 & 349 & $349 \cdot 0$ \\
\hline 2 & $72 \cdot 5$ & 0 & 0 & 23 & $7 \cdot 7$ & 3 & 0.39 \\
\hline 43 & $12 \cdot 6$ & 0 & 0 & 24 & $20 \cdot 9$ & 3 & $0 \cdot 14$ \\
\hline 56 & 30.9 & 0 & 0 & 25 & $2 \cdot 1$ & 5 & $2 \cdot 38$ \\
\hline 61 & $23 \cdot 5$ & 0 & 0 & 29 & $23 \cdot 4$ & 2 & 0.09 \\
\hline 68 & $18 \cdot 0$ & 0 & 0 & 31 & 11.9 & 151 & $12 \cdot 69$ \\
\hline \multirow{2}{*}{69} & $49 \cdot 5$ & 0 & 0 & 32 & 6.9 & 6 & 0.87 \\
\hline & & & & 38 & 4.4 & 19 & $4 \cdot 32$ \\
\hline
\end{tabular}

high frequencies and excessive residual growth, suggesting that methionine synthesis persisted at low rates. Reversion to $\mathrm{Met}^{+}$occurred in four MetI- mutants of strain 251 and in strain 89108. Revertants were not detected, however, in cultures of seven mutant strains listed in Table 2, or in MetI $^{-}$mutants 90,151 , and 153 (Table 3).

$\mathrm{Met}^{-} \times \mathrm{Met}^{-}$transformation. Recombination between the sites of met mutation was investigated as a means of characterizing the mutations and possibly differentiating various mutants. The $26 \mathrm{Met}^{-}$mutants listed in Table 2 were examined in reciprocal transformation tests. As expected of mutations affecting two genes, each of the MetI $\mathrm{I}^{-}$recipients was transformed to $\mathrm{Met}^{+}$by DNA preparations from all of the $14 \mathrm{MetII}^{-}$strains, and vice versa. Intragenic crosses, however, revealed genetic diversity. Tests of strain 89-108 and $28 \mathrm{MetI}^{-}$ mutants of strain 251 identified 14 distinct profiles of transformation (Table 3). Mutants 33 and 79 were indistinguishable in all tests, suggesting that their sites of mutation might be either identical or proximate. Additionally, $47 \mathrm{Metl}^{-}$spontaneous mutants isolated from strain 89 were examined in crosses with the 11 DNAs from strain 251 MetI $^{-}$mutants. Twelve transformation profiles (not shown) were differentiated, five of which resembled profiles illustrated in Table 3. Thus, 21 nonidentical metI mutations were identified in these $76 \mathrm{Sul}^{\mathrm{r}}$ isolates.

Crosses between the MetII ${ }^{-}$strains 5, 23, 24, 25, 29 and 32 and each of the six corresponding DNAs did not yield $\mathrm{Met}^{+}$transformants. Transformation was obtained, however, in crosses between these six recipients and each of the other DNAs. Mutants 3, 4, 6, 8, 21, 22, 31 and 38 were transformed by all heterologous DNAs (results not shown). The findings with these 14 revertible strains suggest that they carry single-site mutations of at least nine metII sites.

Selection of Sulr $\mathrm{Met}^{-}$mutants. It was of interest to compare the mutants isolated by selection with sulphonamides that have different structures. The selection medium for eight of the strain $251 \mathrm{MetI}^{-}$mutants listed in Table 3 contained sulphadiazine at $5 \mu \mathrm{g} \mathrm{ml}^{-1}$ and mutants 151 and 153 came from sulphamethoxazole at $10 \mu \mathrm{g} \mathrm{ml}^{-1}$. Mutant 153 and two strain 89 mutants obtained with sulphadiazine $\left(5\right.$ and $\left.10 \mu \mathrm{g} \mathrm{ml}^{-1}\right)$ displayed similar profiles. The profiles displayed by strain 251 mutants 33 and 79 resembled those of 11 mutants of strain 89 ; three of the 11 were isolated on medium containing $2 \mu \mathrm{g}$ sulphathiazole $\mathrm{ml}^{-1}$ and the remainder were from sulphadiazine at concentrations of 2,5 and $10 \mu \mathrm{g} \mathrm{ml}^{-1}$ (two, four and two mutants, respectively). In spite of their differing mutations and differences between the particular sulphonamide and the concentration used for selection, all of the $\mathrm{MetI}^{-}$mutants examined were resistant to levels of sulphadiazine $\geqslant 10 \mu \mathrm{g} \mathrm{ml}^{-1}$. 


\section{Table 3. Recombination between metI mutational sites}

NEDA-minus-Met medium in multiple Petri dishes was inoculated with each MetI- recipient strain followed by addition of DNA $(0.05 \mathrm{ml}$ containing 5 to $10 \mu \mathrm{g})$ from each MetI- donor; typical results found after incubation are illustrated in Fig. 2. $\mathrm{Met}^{+}$transformants: + , numerous;,$\pm<25 ; \boldsymbol{O}$, none found in test with homologous DNA; 0 , none found in test with heterologous DNA.

\begin{tabular}{|c|c|c|c|c|c|c|c|c|c|c|c|}
\hline \multirow{2}{*}{$\begin{array}{c}\text { Recipient } \\
\text { mutant } \\
\text { designated*: }\end{array}$} & \multicolumn{11}{|c|}{ Transformation with DNA from mutant designated: } \\
\hline & 34 & 35 & 69 & 43 & 56 & 1 & 2 & 61 & 68 & 33,79 & $89-108$ \\
\hline 34 & 0 & + & + & + & + & 0 & + & + & + & + & + \\
\hline 35 & + & O & + & + & + & 0 & + & + & + & + & + \\
\hline 69 & + & + & 0 & \pm & 0 & 0 & \pm & + & + & + & + \\
\hline 43 & + & + & \pm & $\overline{0}$ & 0 & 0 & \pm & + & + & + & + \\
\hline 56 & + & + & $\overline{0}$ & 0 & 0 & 0 & \pm & + & + & + & + \\
\hline 1 & 0 & 0 & 0 & 0 & 0 & 0 & $\overline{0}$ & \pm & \pm & + & + \\
\hline $90 \dagger$ & + & 0 & 0 & 0 & 0 & 0 & \pm & $\bar{t}$ & + & + & + \\
\hline $151 \dagger$ & 0 & 0 & 0 & 0 & 0 & 0 & $\overline{0}$ & 0 & 0 & + & + \\
\hline $153 \dagger$ & 0 & 0 & 0 & 0 & 0 & 0 & 0 & 0 & 0 & 0 & + \\
\hline 2 & + & \pm & \pm & \pm & \pm & 0 & 0 & 0 & 0 & + & + \\
\hline 61 & + & $\bar{t}$ & $\bar{t}$ & $\bar{t}$ & $\bar{t}$ & + & 0 & 0 & 0 & 0 & + \\
\hline 68 & + & + & + & + & + & + & 0 & 0 & 0 & 0 & 0 \\
\hline 33,79 & + & + & + & + & + & + & + & 0 & 0 & 0 & + \\
\hline $89-108$ & + & + & + & + & + & + & + & + & 0 & + & 0 \\
\hline
\end{tabular}

* Mutant 89-108 was isolated from strain 89; the 14 other mutants were from strain 251 .

$\dagger$ DNA was not prepared from this mutant strain.

In contrast, the $14 \mathrm{MetII}^{-}$mutants were isolated on medium containing $2 \mu \mathrm{g}$ sulphadiazine $\mathrm{ml}^{-1}$. Tests of these mutants in pure culture found that their resistance was limited to concentrations $\leqslant 8 \mu \mathrm{g} \mathrm{ml}^{-1}$. The MetII- phenotype apparently did not adapt the cells for competition with the parental strain undergoing residual growth on medium containing $5 \mu \mathrm{g}$ sulphadiazine $\mathrm{ml}^{-1}$.

\section{Return of sulphonamide susceptibility}

The theory that increased resistance to sulphonamides is a pleiotropic effect of certain met mutations requires that a return to sulphonamide susceptibility must accompany the restoration of methionine prototrophy. This was demonstrated unequivocally by the response to sulphadiazine found in $\mathrm{Met}^{+}$derivatives obtained by mutation and transformation.

$\mathrm{Met}^{+}$revertants that arose by spontaneous mutation displayed the parental level of resistance. For example, tests of $14 \mathrm{Met}^{+}$revertants derived from strain $251 \mathrm{MetI}^{-}$mutants 34 and 35 showed that resistance had declined from $10 \mu \mathrm{g} \mathrm{ml}^{-1}$ to $1.0 \mu \mathrm{g} \mathrm{ml}^{-1}$. Also, the resistance of a spontaneous $\mathrm{Met}^{+}$mutant isolated from 89-108 was equal to the parental level of resistance, $0.5 \mu \mathrm{g} \mathrm{ml}^{-1}$. Additional tests of these revertants showed that possible mutations had not occurred in 20 other genes.

Furthermore, a level of resistance similar to that of the $\mathrm{Met}^{+}$parent strain 251 was found in $\mathrm{Met}^{+}$transformants derived by treatment of $\mathrm{Met}^{-}$recipients with DNA from any one of five $\mathrm{MetI}^{-}$mutants or the MetII- mutants 5 and 24 (Table 4). Although the $\mathrm{Met}^{+} \mathrm{Arg}^{+}$strain $\mathrm{CDC}$ is naturally resistant to sulphonamides, its DNA elicited $\mathrm{Met}^{+}$transformants that were Suls. Unaccountably, however, their resistance was not reduced to the parental level. For control purposes, $\mathrm{Arg}^{+}$transformants were isolated from the reaction mixtures containing CDC DNA. These transformants retained the $\mathrm{Met}^{-} \mathrm{Sul}^{\mathrm{r}}$ phenotype typical of the particular recipient.

\section{A second round of sulphadiazine selection}

How will revertants respond to a second challenge with sulphadiazine? The question was explored with a spontaneous mutant isolated from the MetII ${ }^{-}$mutant 38. This $\mathrm{Met}^{+} \mathrm{Sul}^{\mathrm{s}}$ revertant was inoculated on GCMBS medium containing $2.0 \mu \mathrm{g}$ of sulphadiazine $\mathrm{ml}^{-1}$, similar to the first-round selection medium. Sul' ${ }^{\mathrm{r}}$ colonies were picked and tests identified six $\mathrm{MetII}^{-}$ 
Table 4. Levels of sulphadiazine resistance of $\mathrm{Met}^{+}$and $\mathrm{Arg}^{+}$transformants

Cellular suspensions of $\mathrm{MetII}^{-}$mutant 5 and four $\mathrm{MetI}^{-}$strains were treated in DEFT fluid with each indicated DNA $\left(1.0 \mu \mathrm{g} \mathrm{ml}^{-1}\right)$; the uptake of DNA was terminated after 20 min by deoxyribonuclease and samples were plated on NEDA-minus-Met or NEDA-minus-Arg medium. Transformant colonies were purified and inoculated on various media for phenotype characterization. Parent strain 251 , the source of the mutants, is resistant to $1.0 \mu \mathrm{g}$ sulphadiazine $\mathrm{ml}^{-1}$. The levels of sulphadiazine resistance of the $\mathrm{Met}^{-}$recipient strains, as determined in multiple tests, were: mutant $5,4.0 \mu \mathrm{g} \mathrm{ml}^{-1} ;$ mutant 2 , $35 \mu \mathrm{g} \mathrm{ml}^{-1}$; mutant $43,50 \mu \mathrm{g} \mathrm{ml}^{-1}$; mutant $56,25 \mu \mathrm{g} \mathrm{ml}^{-1}$; and mutant $69,30 \mu \mathrm{g} \mathrm{ml}^{-1}$.

\begin{tabular}{|c|c|c|c|c|c|c|}
\hline \multirow[b]{2}{*}{$\begin{array}{l}\text { Recipient } \\
\text { strain }\end{array}$} & \multirow[b]{2}{*}{$\begin{array}{l}\text { DNA donor strain } \\
\text { designated: }\end{array}$} & \multicolumn{2}{|c|}{ Transformants } & \multirow[b]{2}{*}{$\begin{array}{l}\text { Nutritional } \\
\text { phenotype }\end{array}$} & \multicolumn{2}{|c|}{$\begin{array}{c}\text { Resistance to } \\
\text { sulphadiazine } \mu \mathrm{g} \mathrm{ml}^{-1}\end{array}$} \\
\hline & & Selection & $\begin{array}{c}\text { No. } \\
\text { examined }\end{array}$ & & Mean & (range) \\
\hline $\begin{array}{r}\text { Mutant } 5 \\
5 \\
5\end{array}$ & $\begin{array}{l}2,43,56,61,69 \\
\text { CDC } \\
\text { CDC }\end{array}$ & $\begin{array}{l}\mathrm{Met}^{+} \\
\mathrm{Met}^{+} \\
\mathrm{Arg}^{+}\end{array}$ & $\begin{array}{r}40 \\
24 \\
8\end{array}$ & $\begin{array}{l}\mathrm{Met}^{+} \mathrm{Arg}^{-} \\
\mathrm{Met}^{+} \mathrm{Arg}^{-} \\
\mathrm{Met}^{-} \mathrm{Arg}^{+}\end{array}$ & $\begin{array}{l}1 \cdot 0 \\
1 \cdot 2 \\
4 \cdot 1\end{array}$ & $\begin{array}{c}(1 \cdot 0) \\
(1 \cdot 0-3 \cdot 0) \\
(4 \cdot 0-5 \cdot 0)\end{array}$ \\
\hline $\begin{array}{r}\text { Mutant } 2 \\
2 \\
2\end{array}$ & $\begin{array}{l}24 \\
\mathrm{CDC} \\
\mathrm{CDC}\end{array}$ & $\begin{array}{l}\mathrm{Met}^{+} \\
\mathrm{Met}^{+} \\
\mathrm{Arg}^{+}\end{array}$ & $\begin{array}{r}16 \\
26 \\
9\end{array}$ & $\begin{array}{l}\mathrm{Met}^{+} \mathrm{Arg}^{-} \\
\mathrm{Met}^{+} \mathrm{Arg}^{-} \\
\mathrm{Met}^{-} \mathrm{Arg}^{+}\end{array}$ & $\begin{array}{r}1 \cdot 0 \\
2 \cdot 4 \\
32 \cdot 2\end{array}$ & $\begin{array}{c}(1 \cdot 0) \\
(1 \cdot 0-6 \cdot 0) \\
(30 \cdot 0-35 \cdot 0)\end{array}$ \\
\hline $\begin{array}{r}\text { Mutant } 43 \\
43 \\
43\end{array}$ & $\begin{array}{l}24,61 \\
C D C \\
C D C\end{array}$ & $\begin{array}{l}\mathrm{Met}^{+} \\
\mathrm{Met}^{+} \\
\mathrm{Arg}^{+}\end{array}$ & $\begin{array}{r}31 \\
25 \\
8\end{array}$ & $\begin{array}{l}\mathrm{Met}^{+} \mathrm{Arg}^{-} \\
\mathrm{Met}^{+} \mathrm{Arg}^{-} \\
\mathrm{Met}^{-} \mathrm{Arg}^{+}\end{array}$ & $\begin{array}{r}1 \cdot 0 \\
2 \cdot 2 \\
44 \cdot 4\end{array}$ & $\begin{array}{c}(1 \cdot 0) \\
(1 \cdot 0-5 \cdot 0) \\
(35 \cdot 0-50 \cdot 0)\end{array}$ \\
\hline $\begin{array}{r}\text { Mutant } 56 \\
56 \\
56\end{array}$ & $\begin{array}{l}5,24,61 \\
\text { CDC } \\
\text { CDC }\end{array}$ & $\begin{array}{l}\mathrm{Met}^{+} \\
\mathrm{Met}^{+} \\
\mathrm{Arg}^{+}\end{array}$ & $\begin{array}{r}32 \\
8 \\
8\end{array}$ & $\begin{array}{l}\mathrm{Met}^{+} \mathrm{Arg}^{-} \\
\mathrm{Met}^{+} \mathrm{Arg}^{-} \\
\mathrm{Met}^{-} \mathrm{Arg}^{+}\end{array}$ & $\begin{array}{r}1 \cdot 0 \\
2 \cdot 5 \\
24 \cdot 4\end{array}$ & $\begin{array}{c}(1 \cdot 0) \\
(1 \cdot 0-4 \cdot 0) \\
(20 \cdot 0-25 \cdot 0)\end{array}$ \\
\hline $\begin{array}{r}\text { Mutant } 69 \\
69 \\
69\end{array}$ & $\begin{array}{l}5,24,61 \\
\mathrm{CDC} \\
\mathrm{CDC}\end{array}$ & $\begin{array}{l}\mathrm{Met}^{+} \\
\mathrm{Met}^{+} \\
\mathrm{Arg}^{+}\end{array}$ & $\begin{array}{r}23 \\
11 \\
9\end{array}$ & $\begin{array}{l}\mathrm{Met}^{+} \mathrm{Arg}^{-} \\
\mathrm{Met}^{+} \mathrm{Arg}^{-} \\
\mathrm{Met}^{-} \mathrm{Arg}^{+}\end{array}$ & $\begin{array}{r}1 \cdot 0 \\
3 \cdot 2 \\
33 \cdot 9\end{array}$ & $\begin{array}{c}(1 \cdot 0) \\
(2 \cdot 0-5 \cdot 0) \\
(30 \cdot 0-35 \cdot 0)\end{array}$ \\
\hline
\end{tabular}

mutants that could be transformed to $\mathrm{Met}^{+} \mathrm{Sul}^{\mathrm{s}}$ by each of the 25 DNAs from strain $251 \mathrm{Met}^{-}$ mutants. Seven MetI $^{-}$mutants included three with recombination profiles unlike any in Table 3: one was transformed by all DNAs except those of mutants 61 and 68, and two mutants with revertible sites were transformed by all except DNA 1 . The other profiles resembled those of mutants $43,56,61$ and 153 .

In addition, $\mathrm{Met}^{+} \mathrm{Sul}^{\mathrm{s}}$ transformants obtained from MetII ${ }^{-}$mutant 5 by treatment with DNAs from MetI- mutants 2, 43 and 56 were exposed in the second round to $5 \mu \mathrm{g}$ sulphadiazine $\mathrm{ml}^{-1}$. Fifteen $\mathrm{MetI}^{-}$mutants and no MetII ${ }^{-}$mutants were recovered. Their recombination profiles were among those illustrated in Table 3 . Interestingly, none duplicated the profiles of mutants 2,43 or 56 . Thus, the second round met mutations were not constrained by the ancestral met genotypes. In agreement with previous results, $\mathrm{MetII}^{-}$mutants were isolated in the presence of sulphadiazine at a concentration of $2 \mu \mathrm{g} \mathrm{ml}^{-1}$, but not $5 \mu \mathrm{g} \mathrm{ml}^{-1}$.

\section{DISCUSSION}

The relation between sulphonamide resistance and methionine auxotrophy in isogenic gonococci was investigated because of findings with diverse isolates from patients over a period of 40 years. A group of $70 \mathrm{~N}$. gonorrhoeae strains isolated before 1950 displayed resistance to sulphadiazine that ranged between $0 \cdot 2 \mu \mathrm{g} \mathrm{ml}^{-1}$ and $\geqslant 100 \mu \mathrm{g} \mathrm{ml}^{-1}$, and $24(34 \%)$ were $\mathrm{Met}^{-}$ (Catlin \& Reyn, 1982). The resistance of some $\mathrm{Met}^{+}$gonococci presumably was due to structural alterations of dihydropteroate synthase, as described by Ho et al. (1974). Resistance to $\geqslant 35 \mu \mathrm{g}$ sulphadiazine $\mathrm{ml}^{-1}$ was found in eight strains, seven of which were MetI-. Lower levels of resistance characterized other strains, including eight MetII $^{-}$isolates from disseminateo gonococcal infections.

The results given in Tables 1 and 2 support the theory that the high incidence of $\mathrm{Met}^{-} \mathrm{Sul}^{\mathrm{r}}$ gonococci in the 1940s was due to selection of mutants by sulphonamides widely used for therapy 
of various susceptible bacterial diseases. When penicillin replaced sulphonamides in the clinic, the selective advantage of sulphonamide resistance was lost, with the result that the $\mathrm{Met}^{-} \mathrm{Sul}^{\mathrm{r}}$ phenotype virtually disappeared within ten years (Catlin, 1976; Knapp et al., 1985).

$N$. gonorrhoeae strains 89 and 251 used here came from patients on different continents and separated by 30 years. The evolutionary opportunities afforded strain 251 in the postsulphonamide era led to substantial changes (cited in Methods). Nevertheless, numerous metI mutations were easily recovered from both strains by selection with sulphadiazine, sulphamethoxazole or sulphathiazole, and some profiles of metI transformation were similar.

The increased resistance enabling the mutants to grow on sulphonamide-containing medium appears to be a pleiotropic effect of methionine auxotrophy. This theory that the two phenotypic changes are due to one mutation is substantiated by the evidence that $\mathrm{Met}^{-}$revertants derived by spontaneous mutation reacquired sulphonamide susceptibility equal to that of the $\mathrm{Met}^{+} \mathrm{Sul}^{\mathrm{s}}$ parent. Further support for the theory is provided by transformation in which the $\mathrm{Met}^{-} \mathrm{Sul}^{\mathrm{r}}$ traits were introduced or removed together. The selective action of sulphonamides appears to be specific for these met mutations since mutations were not found in 14 genes that encode other biosynthetic functions or six genes that affect responses to other antibacterial agents.

The role of met mutations in sulphonamide resistance can be understood by analogy with the resistance to trimethoprim afforded by thy mutations responsible for a thymine requirement. Sulphonamides and trimethoprim each interrupt a step in the folate pathway, sulphonamides by binding to dihydropteroate synthase and trimethoprim by binding to dihydrofolate reductase (Gale et al., 1981; Harvey, 1982). Inhibition of growth ensues in either case because of the critical role of folates. Tetrahydrofolate is a versatile carrier of activated one-carbon units. The unit can exist in three oxidation states which are interconvertible and are utilized in the synthesis of various cellular components, including methionine, thymidine, purines and formylmethionyl-tRNA $\mathrm{f}$ (Stryer, 1981). $N^{5}, N^{10}$-Methylenetetrahydrofolate is the source of the methyl group used by thymidylate synthase to form deoxythymidylate. The absence of thymidylate synthase activity in mutants that require an exogenous source of thymidine reduces depletion of the pool of tetrahydrofolates. Thus, E. coli Thy mutants gain increased resistance to trimethoprim because of the greater availability of tetrahydrofolate derivatives (Amyes \& Smith, 1974; Harvey, 1982). This resistance provides a way to isolate thy mutations (Stacey \& Simson, 1965).

The enzymes affected by the metI and metII mutations have not been identified. Clues are provided, however, by knowledge of the folate and methionine pathways in $E$. coli (Fig. 1). The met $F$ gene of $E$. coli encodes $N^{5}, N^{10}$-methylenetetrahydrofolate reductase, which reduces $N^{5}, N^{10}$-methylenetetrahydrofolate to $N^{5}$-methyltetrahydrofolate (Rowbury, 1983). The formation of methionine by transfer of this $N^{5}$-methyl group to homocysteine is catalysed in $E$. coli by either of two homocysteine methyltransferases, encoded by met $E$ and $m e t H$ (Smith, 1971). On the other hand, most bacteria produce only one homocysteine methyltransferase (Flavin, 1975).

Homocysteine does not satisfy the requirement imposed by mutations of $\operatorname{met} F$, met $E$ or $\operatorname{met} H$, but it can replace methionine for $\mathrm{MetC}^{-}$mutants, which fail to convert cystathionine to homocysteine due to the absence of cystathionine $\beta$-lyase activity (Rowbury, 1983). Similarly, the MetII ${ }^{-}$gonococcal mutants utilize homocysteine, but not cystathionine. This suggests that they may lack cystathionine $\beta$-lyase or, alternatively, are unable to take up cystathionine. The MetI $^{-}$mutants which utilize only methionine most likely correspond to $E$. coli $\mathrm{MetF}^{-}$. The choice of $N^{5}, N^{10}$-methylenetetrahydrofolate reductase over homocysteine methyltransferase as the missing enzyme activity is based on the similarity of the effects of sulphonamides and trimethoprim on the folate pathway as described above. The absence of $N^{5}, N^{10}$-methylenetetrahydrofolate reductase activity in MetI $^{-}$mutants would eliminate one function that depletes the pool of essential tetrahydrofolate derivatives.

The importance of conserving the pool, according to this model, accounts for the greater resistance conferred by mutations of metI than metII. Whereas $\mathrm{MetI}^{-}$mutants display resistance to $\geqslant 10 \mu \mathrm{g}$ sulphadiazine $\mathrm{ml}^{-1}$, the resistance of MetII- mutants is limited to $\leqslant 8 \mu \mathrm{g} \mathrm{ml}^{-1}$. The sulphadiazine-containing GCMBS medium provides all mutants with methionine. Nevertheless, the $N^{5}, N^{10}$-methylenetetrahydrofolate reductase activity continuing in the presence of 
sulphadiazine would further impair the capacity of MetII ${ }^{-}$mutants to perform activities catalysed by tetrahydrofolate derivatives. The return to the parental level of resistance in $\mathrm{Met}^{+}$ revertants verifies that the metabolic defects imposed by the metI and metII mutations were solely responsible for the differing resistances.

The $76 \mathrm{MetI}^{-}$mutants of strains 251 and 89 examined in tests with DNAs from strain 251 $\mathrm{MetI}^{-}$donors displayed 21 distinct transformation profiles. Thus, sulphonamide selection yields numerous distinguishable mutations. The revertible mutations of mutants 34,35 and 89-108 may represent different base-pair changes. On the other hand, the 11 nonreverting metI mutations that fail to recombine with contiguous mutational sites appear to be deletions of various nucleotide sequences (Table 3). The deletion of mutant 135 spans a great length of the met $I$ locus. The findings suggest that the genetic fine structure of metI could be analysed by deletion mapping (Smith \& Childs, 1966).

The expert technical assistance of Patricia Reddy and Dorothy Casimere is gratefully acknowledged. This work was supported by US Public Health Service research grant AI-02353 from the National Institute of Allergy and Infectious Diseases.

\section{REFERENCES}

Amyes, S. G. B. \& Smith, J. T. (1974). Trimethoprim action and its analogy with thymine starvation. Antimicrobial Agents and Chemotherapy 5, 169-178.

Breitman, T. R., Finkleman, A. \& Rabinovitz, M. (1971). Methionineless death in Escherichia coli. Journal of Bacteriology 108, 1168-1173.

Brown, G. M. (1962). The biosynthesis of folic acid. II. Inhibition by sulfonamides. Journal of Biological Chemistry 237, 536-540.

Catlin, B. W. (1967). Genetic studies of sulfadiazineresistant and methionine-requiring Neisseria isolated from clinical material. Journal of Bacteriology 94, 719-733.

Catlin, B. W. (1973). Nutritional profiles of Neisseria gonorrhoeae, Neisseria meningitidis, and Neisseria lactamica in chemically defined media and the use of growth requirements for gonococcal typing. Journal of Infectious Diseases 128, 178-194.

Catlin, B. W. (1974). Genetic transformation of biosynthetically defective Neisseria gonorrhoeae clinical isolates. Journal of Bacteriology 120, 203-209.

CATLIN, B. W. (1976). Evolution of Neisseria gonorrhoeae-1975. In Microbiology-1976, pp. 453-466. Edited by D. Schlessinger. Washington, DC: American Society for Microbiology.

CATLIN, B. W. (1978). Characteristics and auxotyping of Neisseria gonorrhoeae. Methods in Microbiology 10, $345-380$.

CATlin, B. W. \& REYN, A. (1982). Neisseria gonorrhoeae isolated from disseminated and localised infections in pre-penicillin era. British Journal of Venereal Diseases 58, 158-165.

Catlin, B. W. \& Shinners, E. N. (1985). Gonococcal protein I: genetic dissection and linkage associations of nmp-1. In The Pathogenic Neisseriae, pp. 123-129. Edited by G. K. Schoolnik. Washington, DC: American Society for Microbiology.

DeEs, J. E. \& Colston, J. A. C. (1937). The use of sulfanilamide in gonococcic infections. Journal of the American Medical Association 108, 1855-1858.

Flavin, M. (1975). Methionine biosynthesis. In Metabolic Sulfur Compounds, vol. VII, Metabolic Pathways, pp. 457-503. Edited by D. M. Greenberg. New York: Academic Press.

Gale, E. F., Cundliffe, E., Reynolds, P. E.,
Richmond, M. H. \& Waring, M. J. (1981). The Molecular Basis of Antibiotic Action, 2nd edn, pp. 820, 29-32, 551. London: John Wiley.

HaRVEY, R. J. (1982). Synergism in the folate pathway. Reviews of Infectious Diseases 4, 255-260.

Ho, R. I., Corman, L., Morse, S. A. \& Artenstein, M. S. (1974). Alterations in dihydropteroate synthetase in cell-free extracts of sulfanilamide-resistant Neisseria meningitidis and Neisseria gonorrhoeae. Antimicrobial Agents and Chemotherapy 5, 388-392.

KNAPP, J. S., MulKs, M. H., Lind, I., ShORT, H. B. \& Clark, V. L. (1985). Evolution of gonococcal populations in Copenhagen, Denmark, 1928-1979. In The Pathogenic Neisseriae, pp. 82-88. Edited by G. K. Schoolnik. Washington, DC: American Society for Microbiology.

Koelbl, J. A. \& Catlin, B. W. (1986). Vancomycin hypersusceptibility in Neisseria gonorrhoeae isolated from patients involves diverse mutations. Antimicrobial Agents and Chemotherapy 29, 687-695.

KoHN, H. I. \& HARRIS, J. S. (1942). Methionine made an essential growth factor by cultivation of $E$. coli in the presence of methionine and sulfanilamide. Journal of Bacteriology 44, 717-718.

Lopez, P., Espinosa, M., GReenberG, B. \& LaCKs, S. A. (1987). Sulfonamide resistance in Streptococcus pneumoniae: DNA sequence of the gene encoding dihydropteroate synthase and characterization of the enzyme. Journal of Bacteriology 169, $4320-4326$.

Pato, M. L. \& Brown, G. M. (1963). Mechanisms of resistance of Escherichia coli to sulfonamides. Archives of Biochemistry and Biophysics 103, 443-448.

REYN, A. (1961). Sensitivity of $N$. gonorrhoeae to antibiotics. British Journal of Venereal Diseases 37, 145-157.

Roland, S., Ferone, R., Harvey, R. J., Styles, V. L. \& MORRISON, R. W. (1979). The characteristics and significance of sulfonamides as substrates for Escherichia coli dihydropteroate synthase. Journal of Biological Chemistry 254, 10337-10345.

RowBURY, R. J. (1983). Methionine biosynthesis and its regulation. In Amino Acids. Biosynthesis and Genetic Regulation, pp. 191-211. Edited by K. M. Herrmann \& R. L. Somerville. London: AddisonWesley. 
Shinners, E. N. \& Catlin, B. W. (1982). Arginine and pyrimidine biosynthetic defects in Neisseria gonorrhoeae strains isolated from patients. Journal of Bacteriology 151, 295-302.

SMith, D. A. (1971). S-Amino acid metabolism and its regulation in Escherichia coli and Salmonella typhimurium. Advances in Genetics 16, 141-165.

SmITH, D. A. \& ChILDS, J. D. (1966). Methionine genes and enzymes of Salmonella typhimurium. Heredity 21, 265-286.
Stacey, K. A. \& Simson, E. (1965). Improved method for the isolation of thymine-requiring mutants of Escherichia coli. Journal of Bacteriology 90, 554-555. STRYER, L. (1981). Biochemistry, 2nd edn, pp. 491-495, 526-528, 656-657. San Francisco: W. H. Freeman. Woods, D. D. (1962). The biochemical mode of action of the sulphonamide drugs. Journal of General Microbiology 29, 687-702. 